\title{
Prenatal stress exposure is associated with increased dyspnoea perception in adulthood
}

\author{
To the Editor:
}

Dyspnoea is the aversive cardinal symptom in various prevalent conditions such as respiratory, cardiovascular and neuromuscular diseases and is associated with great individual and socioeconomic burden [1]. Over the past years, several physiological and also psychological factors have been demonstrated to affect the perception of dyspnoea $[1,2]$. For example, high levels of anxiety in adulthood were associated with increased dyspnoea perception in patients with asthma or chronic obstructive pulmonary disease (COPD), but also in healthy controls [2]. Moreover, adverse, separation-related experiences in childhood were linked to the subsequent development of increased anxiety and dyspnoea [3]. However, the effects of adverse experiences in early, prenatal life on dyspnoea perception remain widely unknown, although prenatal exposure to maternal stress and anxiety has convincingly been related to the development of other health and behavioural problems later in life, including impairments of the respiratory control system and high anxiety levels [4-9]. Therefore, this study investigated the relationship between prenatal exposure to maternal stress and the perception of dyspnoea in adulthood 28 years later.

Subjects were recruited from the "Leuven Cohort", a longitudinal study that started in 1986 with 86 pregnant mothers and their firstborn children. The study examines the neurobehavioral effects of prenatal exposure to maternal stress on fetal, infant and childhood development, continuing into adulthood [10]. At study entry, the sample of mothers consisted of healthy Belgian women without history of psychiatric disorders. Maternal stress levels during pregnancy were operationalised as trait anxiety levels and assessed with the validated State-Trait Anxiety Inventory [11]. In addition, the following variables with known impact on early life development were obtained: duration of pregnancy (days), birthweight (g), maternal smoking during pregnancy (number of cigarettes per day), maternal caffeine consumption during pregnancy $\left(\mathrm{mg}^{-\mathrm{day}^{-1}}\right)^{-}$and maternal alcohol consumption during pregnancy $\left(\mathrm{mg}^{\mathrm{day}}{ }^{-1}\right)$.

From the original cohort, 40 healthy adults could be included. After obtaining written informed consent and an anamnestic interview, spirometric lung function was measured. Additionally, levels of state and trait anxiety, dyspnoea-specific anxiety and somatic symptom burden were assessed with validated questionnaires [11-13].

Subsequently, their perception of dyspnoea was examined in two magnitude estimation tasks (MET), during which four inspiratory threshold loads (Respironics, Parsippany, NJ, USA) with different resistances $\left(0,5,20\right.$ and $\left.40 \mathrm{cmH} \mathrm{H}_{2} \mathrm{O} \cdot \mathrm{L}^{-1} \cdot \mathrm{s}^{-1}\right)$ were repeatedly being presented. Subjects wore a nose clip and breathed through an antibacterial filter being connected to a two-way, nonrebreathing valve (Hans Rudolph Inc., Shawnee, KS, USA). The inspiratory port was connected to a tube (diameter $2 \mathrm{~cm}$; length $150 \mathrm{~cm}$ ) where threshold loads were introduced. In the first MET, subjects breathed through the loads for one inspiration and rated the intensity of dyspnoea on a Borg scale [14]. Each load was presented four times in random order. In the second MET, subjects breathed for five subsequent inspirations through the loads and rated both the intensity and unpleasantness of dyspnoea on a Borg scale [14]. Each load was presented twice in random order.

For the analyses, subjects were grouped into a low prenatal stress group (LS) and a high prenatal stress group (HS) as in previous studies [10]. Grouping was based on trait anxiety ratings [11] of their mothers during the 12 th to $22 \mathrm{nd}$ week of pregnancy (low $<75$ th versus high $\geqslant 75$ th percentile). Perceptual

@ERSpublications

Prenatal exposure to maternal stress is associated with increased perception of dyspnoea in adulthood 28 years later http://ow.ly/M6EH30d1NEQ

Cite this article as: von Leupoldt A, Mangelschots E, Niederstrasser NG, et al. Prenatal stress exposure is associated with increased dyspnoea perception in adulthood. Eur Respir J 2017; 50: 1700642 [https://doi. org/10.1183/13993003.00642-2017]. 
sensitivity for dyspnoea was calculated with individual regression slopes (Borg scores against load resistance) [15]. Groups were compared with independent samples t-tests or Mann-Whitney U-tests, respectively. Additional Spearman correlations were calculated for dyspnoea sensitivity slopes. Data are presented as group means $( \pm \mathrm{SD})$ and were analysed using SPSS 24 software (SPSS Inc., Chicago, IL, USA) using a statistical significance threshold of $\alpha<0.05$.

Group characteristics including data of the mothers during pregnancy are presented in table 1. As expected, trait anxiety ratings of the mothers during the 12th to 22 nd week of pregnancy were significantly different between groups $(\mathrm{p}<0.001)$. No significant group differences were observed in other characteristics of the tested subjects or their mothers $(p>0.23)$.

No significant group differences were observed in the slopes for dyspnoea intensity in the first, single-breath MET (HS 0.17 \pm 0.06 ; LS $0.15 \pm 0.07 ; \mathrm{p}=0.53$; figure 1a) and in the second, five-breath MET (HS $0.20 \pm 0.03$; LS $0.16 \pm 0.08 ; \mathrm{p}=0.30$; figure $1 \mathrm{~b}$ ). However, the HS group demonstrated significantly higher slopes for dyspnoea unpleasantness than the LS group (HS $0.20 \pm 0.03$; LS $0.15 \pm 0.08$; p $<0.01$; figure $1 \mathrm{c}$ ). In addition, the slopes for dyspnoea unpleasantness showed a significant positive correlation with maternal stress levels ( $\mathrm{rho}=0.34, \mathrm{p}<0.05$; figure $1 \mathrm{~d}$ ), but not with other variables of the subjects or their mothers $($ rho $<0.30, \mathrm{p}>0.06)$.

The present results suggest that prenatal exposure to maternal stress is associated with increased perception of dyspnoea, especially its affective unpleasantness, in adulthood 28 years later. This is in line with previous human and animal studies demonstrating that adverse early life experiences such as being exposed as a fetus to maternal stress, is related to the development of health and behavioural problems later in life [4-9]. However, the specific underlying mechanism for the association between prenatal stress exposure and dyspnoea perception in adulthood observed in the present study remains unclear.

Several potentially contributing factors pertaining to current characteristics of the tested subjects $[1,2]$ including lung function, age, weight, height, gender, general and dyspnoea-specific anxiety levels as well as somatic symptom burden were unrelated to the present findings. Similarly, potential factors related to pregnancy [5, 7] such as duration of pregnancy, birthweight and maternal consumption of cigarette smoke, caffeine and alcohol during pregnancy were not related to the present findings. Therefore, future studies are required to test further potential mechanisms that might underlie the observed association between early life adversity and perception of dyspnoea later in life. These studies might include measures

\begin{tabular}{|c|c|c|c|}
\hline Characteristics & $\begin{array}{l}\text { Low prenatal } \\
\text { stress }\end{array}$ & $\begin{array}{l}\text { High prenatal } \\
\text { stress }\end{array}$ & p-value \\
\hline Age years & $27.79 \pm 0.43$ & $27.75 \pm 0.48$ & 0.82 \\
\hline Female/male ${ }^{\#} \mathrm{n} / \mathrm{n}$ & $16 / 14$ & $4 / 6$ & 0.47 \\
\hline FEV $1 \%$ predicted & $96.43 \pm 14.46$ & $95.35 \pm 9.39$ & 0.75 \\
\hline Height cm & $175.48 \pm 0.11$ & $173.70 \pm 0.10$ & 0.64 \\
\hline Weight kg & $70.97 \pm 10.82$ & $67.92 \pm 12.22$ & 0.46 \\
\hline Current trait anxiety" & $36.62 \pm 8.59$ & $38.11 \pm 6.57$ & 0.64 \\
\hline Current state anxiety ${ }^{\pi}$ & $32.14 \pm 7.98$ & $33.89 \pm 8.24$ & 0.46 \\
\hline Current dyspnoea catastrophising ${ }^{+}$ & $10.46 \pm 11.10$ & $9.11 \pm 10.88$ & 0.88 \\
\hline Current somatic symptoms $s^{\S}$ & $20.75 \pm 3.03$ & $20.00 \pm 2.24$ & 0.50 \\
\hline Maternal trait anxiety at $12-22$ weeks of pregnancy" & $33.00 \pm 5.48$ & $49.07 \pm 4.80$ & $<0.001$ \\
\hline Duration of pregnancy days & $272.43 \pm 10.88$ & $273.80 \pm 9.87$ & 0.73 \\
\hline Birthweight $g$ & $3285.33 \pm 474.67$ & $3451.00 \pm 516.75$ & 0.36 \\
\hline $\begin{array}{l}\text { Maternal smoking during pregnancy number of } \\
\text { cigarettes per day }\end{array}$ & $0.57 \pm 1.92$ & $1.20 \pm 1.87$ & 0.23 \\
\hline $\begin{array}{l}\text { Maternal caffeine consumption during pregnancy } \\
\mathrm{mg} \cdot \mathrm{day}^{-1}\end{array}$ & $292.89 \pm 214.65$ & $240.79 \pm 85.83$ & 0.46 \\
\hline $\begin{array}{l}\text { Maternal alcohol consumption during pregnancy } \\
\mathrm{mg} \cdot \mathrm{day}^{-1}\end{array}$ & $1.32 \pm 1.76$ & $2.93 \pm 3.42$ & 0.29 \\
\hline
\end{tabular}

Data are presented as mean \pm SD, unless otherwise stated. Whereas trait anxiety ratings of the mothers during the 12th to 22nd week of pregnancy are significantly different between groups, there are no significant group differences in other characteristics. FEV1: forced expiratory volume in $1 \mathrm{~s}$. \#: analysed with chi-squared-test; I: $_{\text {: }}$ measured with State-Trait Anxiety Inventory (STAl); ${ }^{+}$: measured with Breathlessness Catastrophizing Scale (BCS); ${ }^{\text {\&: }}$ : measured with PHQ-15 (Patient Health Questionnaire). 

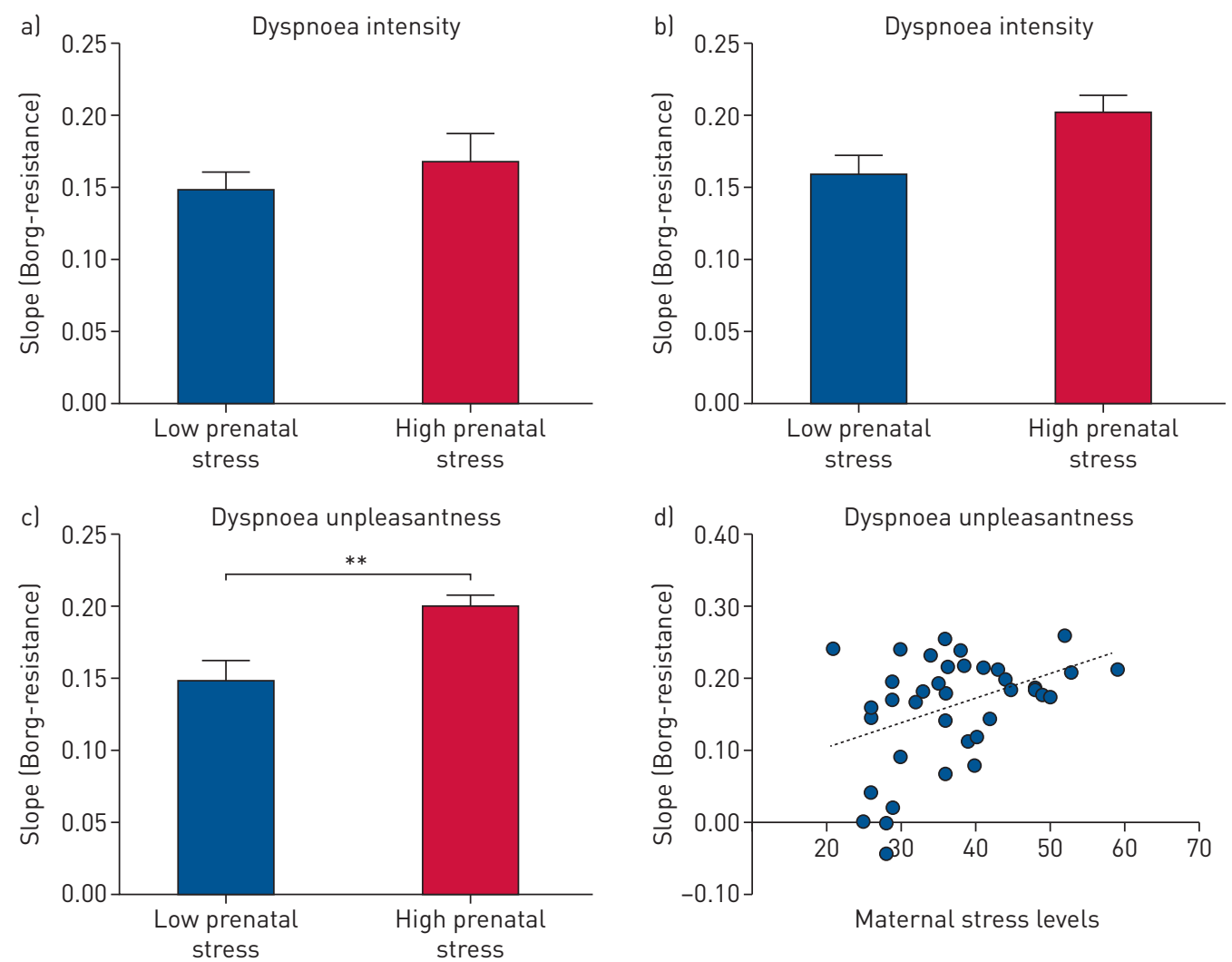

FIGURE 1 Perceptual sensitivity for dyspnoea expressed as group means with standard errors for individual regression slopes (Borg scores against load resistance) for a) dyspnoea intensity during the single breath magnitude estimation tasks (MET), b) dyspnoea intensity during the five-breath MET and cl dyspnoea unpleasantness during the five-breath MET. d) Significant correlation between perceptual sensitivity for dyspnoea unpleasantness during the five-breath MET (Borg scores against load resistance) and maternal stress levels (State-Trait Anxiety Inventory) during the 12 th to 22 nd week of pregnancy. ${ }^{* *}$ : $p<0.01$.

of the autonomic nervous system, the hypothalamic-pituitary-adrenal axis, the endogenous opioidergic and chemosensitive systems as well as functional and structural measures of the brain, which have not only been suggested to be impacted by prenatal stress exposure [5-8], but are also involved in the processing of dyspnoea [2, 3, 9].

Future studies should also address the limitations of the present study such as the rather small sample size, which is partly related to the relatively small original cohort. Moreover, the use of inspiratory threshold loads for the experimental induction of transient dyspnoea sensations only mirrors some facets of dyspnoea (i.e. "increased work and effort of breathing") [1,2], and might not be fully comparable with other, more sustained dyspnoea experiences outside the laboratory. Finally, our findings in healthy, younger adults might not be generalisable to patients that frequently experience dyspnoea, especially when paralleled by older age such as commonly observed in COPD. Therefore, studies are needed that examine the role of early life adversity on dyspnoea perception later in life in dyspnoeic patients with respiratory, cardiovascular and neuromuscular diseases. If the present findings replicate in these future studies, it would not only improve our knowledge on potential mechanisms involved in dyspnoea perception, but also warrant interventions to reduce maternal stress in pregnancy in order to decrease symptom burden in future patients with dyspnoea.

In summary, prenatal exposure to maternal stress is associated with increased perception of dyspnoea in adulthood in healthy subjects. Future studies are needed to examine the underlying mechanism for this association and the respective effects of early life adversity in patients suffering from dyspnoea.

Andreas von Leupoldt $\odot^{1}$, Eline Mangelschots ${ }^{1}$, Nils Georg Niederstrasser ${ }^{1,2}$, Marijke Braeken ${ }^{1,3}$, Thibo Billiet ${ }^{4}$ and Bea R.H. Van den Bergh ${ }^{1,5}$

${ }^{1}$ Health Psychology, University of Leuven, Leuven, Belgium. ${ }^{2}$ School of Sport, Exercise and Health Sciences, Loughborough University, Loughborough, UK. ${ }^{3}$ Rehabilitation Sciences and Physiotherapy, Faculty of Medicine and Life Sciences, Hasselt University, Hasselt, Belgium. ${ }^{4}$ Dept of Radiology, University Hospitals Leuven, Leuven, Belgium. ${ }^{5}$ Dept of Welfare, Public Health and Family, Flemish Government, Brussels, Belgium. 
Correspondence: Andreas von Leupoldt, Health Psychology, University of Leuven, Tiensestraat 102, B-3000 Leuven, Belgium. E-mail: andreas.vonleupoldt@ppw.kuleuven.be

Received: March 272017 | Accepted after revision: May 202017

Support statement: This study was partly supported by a grant from the European Commission Seventh Framework Programme (FP7-HEALTH.2011.2.2.2-2 BRAINAGE, Grant agreement no: 279281) to B.R.H. Van den Bergh and an infrastructure grant from the Herculesstichting, Belgium (AKUL/13/07) to A. von Leupoldt. A. von Leupoldt is supported by the "Asthenes" long-term structural funding Methusalem grant (\# METH/15/011) by the Flemish Government, Belgium. Funding information for this article has been deposited with the Crossref Funder Registry.

Conflict of interest: Disclosures can be found alongside this article at erj.ersjournals.com

\section{References}

1 Laviolette L, Laveneziana P. ERS Research Seminar Faculty. Dyspnoea: a multidimensional and multidisciplinary approach. Eur Respir J 2014; 43: 1750-1762.

2 Mahler DA, O'Donnell DE. Dyspnea: Mechanisms, Measurement, and Management. 3rd Edn. Boca Raton, CRC Press, 2014.

3 Preter M, Klein DF. Lifelong opioidergic vulnerability through early life separation: a recent extension of the false suffocation alarm theory of panic disorder. Neurosci Biobehav Rev 2014; 46: 345-351.

4 Kingston D, Tough S, Whitfield H. Prenatal and postpartum maternal psychological distress and infant development: a systematic review. Child Psychiatry Hum Dev 2012; 43: 683-714.

5 Lewis AJ, Galbally M, Gannon T, et al. Early life programming as a target for prevention of child and adolescent mental disorders. BMC Med 2014; 12: 33

6 Rakers F, Rupprecht S, Dreiling M, et al. Transfer of maternal psychosocial stress to the fetus. Neurosci Biobehav Rev 2017; in press [https://doi.org/10.1016/j.neubiorev.2017.02.019].

7 Van den Bergh BRH, Mulder EJH, Mennes M, et al. Antenatal maternal anxiety and stress and the neurobehavioural development of the fetus and child: links and possible mechanisms. A review. Neurosci Biobehav Rev 2005; 29: 237-258.

8 Braeken MA, Kemp AH, Outhred T, et al. Pregnant mothers with resolved anxiety disorders and their offspring have reduced heart rate variability: implications for the health of children. PloS One 2013; 8: e83186.

9 Rousseau JP, Tenorio-Lopes L, Baldy C, et al. On the origins of sex-based differences in respiratory disorders: lessons and hypotheses from stress neuroendocrinology in developing rats. Respir Physiol Neurobiol 2017; in press [https://doi.org/10.1016/j.resp.2017.03.013].

10 Mennes M, Van den Bergh B, Lagae L, et al. Developmental brain alterations in 17 year old boys are related to antenatal maternal anxiety. Clin Neurophysiol 2009; 120: 1116-1122.

11 Spielberger CD, Gorsuch RL, Lushene RE. Manual for the State-Trait Anxiety Inventory. Palo Alto, Consulting Psychologists Press, 1970.

12 Solomon BK, Wilson KG, Henderson PR, et al. A breathlessness catastrophizing scale for chronic obstructive pulmonary disease. J Psychosom Res 2015; 79: 62-68.

13 Kroenke K, Spitzer RL, Williams JBW. The PHQ-15: validity of a new measure for evaluating the severity of somatic symptoms. Psychosom Med 2002; 64: 258-266.

14 Borg GA. Psychophysical bases of perceived exertion. Med Sci Sports Exerc 1982; 14: 377-381.

15 Kifle Y, Seng V, Davenport PW. Magnitude estimation of inspiratory resistive loads in children with life-threatening asthma. Am J Respir Crit Care Med 1997; 156: 1530-1535. 